\title{
XXXV. Researches in regard to the manner in which natural bodies exhibit colours, and experiments on a new theory of that phænomenon
}

\section{S.F. Hermbstadt}

To cite this article: S.F. Hermbstadt (1804) XXXV. Researches in regard to the manner in which natural bodies exhibit colours, and experiments on a new theory of that phænomenon, Philosophical Magazine Series 1, 18:71, 201-207, DOI: 10.1080/14786440408676478

To link to this article: http://dx.doi.org/10.1080/14786440408676478

\section{Published online: 18 May 2009.}

\section{Submit your article to this journal $\longleftarrow$}

\section{山 Article views: 2}


The experiments arrange themselves under the following heads :

1st, On the affinities which exist betwixt lime, clay, and silex, and carbon, in temperatures from $150^{\circ}$ to $170^{\circ}$ of Wedgewood.

ed, On the affinities. which exist betwixt carbon and ores variously compounded, judging comparatively from their metallic results in fusion.

$3 \mathrm{~d}$, On the affinities which exist betwixt carbon and primary and secondary ores of iron, arranged according to their former classification, judging also comparatively from their metallic results.

[To be continued.]

XXXV. Researches in regard to the Manner in which $\mathrm{Na}$ tural Bodies exhilbit Colours, and Experiments on a new Theory of that Phonomenon. By S. F. Hermbstadt*.

First Part-which contains an Examination of the Question, Whether Light be a simple Sulstance?

T TE colour of any object considered as a phænomenon is the result of the sensation impressed on the organ of sight by the effect of the object, and can no further be explained. If the result of this effect is to be defined from physical causes, it is then necessary to follow its producing causes to discover them if possible, and to deduce from them a rational explanation consistent with natural principles.

If we set out from any other principle, the effective causes are considered as accessory things; and no other result can be obtained from our researches than hypothesis susceptible of any modification, and for that reason insufficient.

It was from this principle that the antient philosophers proceeded when they wished to give a proper idea of the production of colours; and therefore it was natural that the hypothesis they formed should be subject to any modification, and readily give place to other hypotheses.

Newton himself, who without doubt is the greatest among the modern philosophers, did not render his hypothesis in regard to light and colours perfectly free from this objection. The experiments which he first made in the year 1666 on the refraction of light, gave him reason to observe

* From Neves Allgemeines Fournal dir Cbemit, by Hermbstadt, Klaproth, \&c. vol. ii. no. $x$. Berlin $\mathrm{z} \varepsilon 03$. 
its close connection with the colours of bodies, and to form from it a system which, as a monument of human ingemaity, is worthy of admiration.

Some of the suppopts of this system of colours, which at present is made the ground of the explanation given of the phenomena of colours, have been shaken by Euler's hypothesis; but it can by no means be entirely overturned.

Newton's experiments on the refraction of the rays of light, have undoubtedly proved that light must be considered as the first and only cause of all colours, and be made the principle on which they are explained.

But when we found on it the hypothesis, that white light is a mixture of the seven simple coloured rays, which can no longer be decomposed, and when this hypothesis is made the foundation of another, to show how the natural bodies exhibit their colours according as they reflect this or that ray of light and absorb the rest, - this to me appears to be merely an auxiliary hypothesis, capable of explaining the conscquence in part, but by no means entirely.

Had Newton, the celebrated author of this system, been as good a chemist as he was a geometrician and philosopher; and had the knowledge of chemistry been as widely extended in his time as it is at present; that great man, as modest as he was free from prejudice, would in the prosecution of his discoveries have proceeded to the first causes; and these researches would have exhibited to so philosophical and accurate an experimenter the object of his inquiries in a different point of view.

This, however, was not the case. Newton, and most of his followers who employed themselves with researches on this subject, examined rather the refrangibility and reflexibility of light than its intimate nature; and therefore it was unavoidable that phænomena should either escape or be concealed from them, which are every moment produced by the action of light, and which in its effects act a distinguished part as the means of producing colours.

Some new experiments which I made on light, and a repetition of those of others, have exhibited to me phænomena which seem to merit attention, as they may, serve to enable us to form some opinion in regard to the object in question.

'That I may pursue these experiments in systematic order, I shall here mention the ideas which gave birth to them: they were as follows:

1st, Is the white colourless light a simple and not a compound substance? 
od, Is it the product of a mixture of two heterogeneous substances? and in this case, what are the compounding parts?

$3 d$, Does light consist or not in a mixture of seven differently coloured rays? and, if the latter be the case, how and under what circumstances does light act as a medium for the production of colours?

4th, What influence have the matters which in contact with light produce colours on the change of its mixture?

In regard to answering the first question, it will be necessary to determine in general, if possible, whether any thing can exist actually perceptible to the senses in the simple state.

As far as our experience in the knowledge of nature permits us to judge, we must admit among material objects in general, and among the more subtle matters in particular, an incessant and mutual action, which is so powerful, that, in the moment, when we endeavour to disengage simple substances from their mixtures, they again enter into new combinations, and exercise on each other a productive power which never ceases.

It hence follows, that the impression by which these matters affect our senses must be considered either as the result of new mixtures; or it must be admitted that these matters, by their mixing and productive power, are capable of exciting ideas of their specific and individual existence.

If this mode of considering the subject be applied to light, it follows, that it must be considered as the result of the mixture of two different component parts. But here a question naturally arises, What are the principles which produce light, considered as the product of their mixture?

As the answer to this question cannot be founded on any question a priori, it must be explained by experiment ; for it is the result of a research respecting light that can pave the way to a solution of it. With this view the following experiments were made:

\section{Experiment I.}

On a bright summer day, when the horizon was obscured by no cloud, a bundle of rays was introduced into a darkened rqom in such a manner as to cover the bulbs of two thermometers suspended in a perpendicular direction: one of these thermometers, which I shall call $A$, was at the distance of 12 inches, and the other, B, at the distance of 24 , reckoning from the point where the light flowed in.

Olservation.-In the course of ten minutes the mercury 
in the thermometer $\mathrm{A}$ stood at $15^{\circ}$ of Reaumur, and that in $\mathrm{B}$ at $14^{\circ}$. The former, therefore, was the temperature of the light itself.

\section{Experiment II.}

I let the above apparatus remain without any change, but suspended near the thermometer B another, $C$, the bulb of which was covered with a mixture of chalk and clear gum water, and completely dried.

Olservation.-At the end of ten minutes the temperature of the thermometers A and B was the same: in C the mercury stood only at 12 degrees.

\section{Experiment III.}

I again left the apparatus in the same state, but in place of the thermometer $\mathrm{C}$ substituted a new one, $\mathrm{D}$, the bulb of which was covered with a mixture of gum water and vermilioin completely dried.

Olservation.-At the end of ten minutes the mercury in $\mathrm{A}$ and $\mathrm{B}$ was in the same state as before; but in the thermometer $\mathrm{D}$, the bulb of which had been covered with vermilion, it stood at 17 degrees.

\section{Experiment IV.}

In the like manner I suspended near the thermometer B another, $E$, the bulb of which was painted black, with a mixture of lamp-black and gum water.

Olservation.-At the end of ten minutes the temperature of the thermometers $\mathrm{A}$ and $\mathrm{B}$ was as before; but the one $\mathrm{E}$, painted with lamp-black, exhibited the temiperature of $20^{\circ}$.

The results of these experiments were striking, but $I$ was uncertain on what principle I could explain them. Two explanations only were possiblc. 1st, Either the colours which I employed act as conductors of heat : or, 2d, They have different degrees of power to extricate heat from light. To ascertain these points I made the following experiments :

\section{Experiment V.}

I took three cylindric glasses of equal thickness, and filled one with dry pounded chalk, another with dry pounded cinnabar, and the third with burnt lamp-black. In each of these glasses I placed the bulb of a thermometer, in such a manner that it was every where covered by the pulverized substance. The three glasses were then deposited in a small wooden box, and hot sand being poured over them, they were left at rest for ten minutes.

Observation.-The temperature of the sand was now 50 
degrees of Reaumur, the thermometer in the chalk indicated the temperature of 35 degrees, that in the cinnabar 40 , and that in the lamp-black 35 .

It heace follows, therefore, that the conducting power of these substances for heat is as little proportioned as their capacities for it to that heat which the light excites in them: otherwise the lamp-black must have acquired the greatest temperature; whereas it exhibited the lowest, and consequently showed the least power for conducting heat *

These results, therefore, are a sufficient proof that the light, when it acts on substances of different colours, is capable of producing different degrees of beat, if in their former state they were free from heat.

But it is worthy of remark, that the thermometer painted with chalk exhibited a lower temperature than that of the light which fell upon it; and this shows that white light possesses rather the property of extracting heat from colourless bodies than producing in them heat: which agrees with some other experiments.

If the results of these expcriments, therefore, be employed to determine whether light be a simple substance, or a product of the mixture of two different component parts, we are naturally led to adopt the latter idea, namely, that light is not a simple but a compound substance.

We are thus conducted to the answering of the second question, What are the component parts of light? We are taught by the above experiments, that chalk, when it comes into contact with a colourless ray of light, not only produces no heat, but even lessens the absolute heat of the light; and on the other hand, that lamp-black in contact with light is capable of producing the greatest degree of heat.

The latter is the case also when other black objects are subjected to the action of the light, and is confirmed in a striking manner by the well-known experiment, that snow under a piece of black cloth meits much sooner than under white.

It hence follows also, and this is agreeable to Newton's

* The author's inference is in some respects incorrect. The.experiment was instituted to determine whether the coloters he empleyed actcd 2s conductors of heat, or had different degrees of power to exticate heut from light. The result only proves a certain truth resperting the conducting power of the substances employed. The fower of all hodies to tiansmit heat is, in some degree ar least, as their densities. Their colours also may affect the result; but from dissimilar substanecs we apprehend no accu ate inference can be drawn respecting the pojnt in question. -EDIT. 


\section{Manner in which Natural Bodies exhilit Colours.}

principles, that black objects must be considered as those which absorb the light, and capable of depriving it of its luminous property : on the other hand, those must be considered as white or colourless objects which reflect the light that falls upon them, and for this reason appear white.

But here arises another question-If dark objects destroy the action of the light which falls upon them, while white objects do not, what is the efficient cause of this difference? This question may be easily answered on the principles of Newton by this observation, that black objects absorb the light, and white reflect it.

This explanation, however, is merely an auxiliary hypothesis to attempt to explain something, but it by no means explains the result. Should it be explained on satisfactory grounds, a second question will arise, namely, Why is light absorbed by black objects, and not by white? Is this effect accompanied by particular phænomena, or not? And if this be the case, What are the phænomena which are exhibited for our observation?

If the above experiments be made the ground for an explanation of this point, it thence follows, that in the moment when light is deranged in its luminous action by a black object, an exaltation of its temperature takes place.

But the exaltation of the temperature of a body supposes the existence of free heat. If bodies, however, in a state of rest, exposed to the action of light, can on no good grounds be considered as capable of themselves to extricate heat; and if heat is produced by their contact with the rays of light which are not hot of themselves, light must be considered as that object which contains the principles sufficient for the disengagement of heat.

But if the heat combined with light cannot exercise an action till the light is brought into contact with another object, it must be combined with it in a different form. This union or mixture of two heterogeneous bodies in a new product supposes an affinity between them; and this is a sufficient proof that light must be considered as the product of the mixture of caloric and another substance, which unite by the power of affinity.

We hence see by what means light, in consequence of its action on some bodies, can produce heat, and why this is not the case with others. If an object, therefore, is capable of exciting heat by its contact with light, its attractive power for the matter that produces light must be greater than the attractive power of this matter for caloric. Hence it follows, that the productive matter of light is miscible with other 
other matters, and consequently subject to the general laws of chemical or mixing affinity, which places its materiality beyond all doubt. It follows likewise that colourless badies for this reason when they come into contact with light can produce no heat, because their attraction for the producing matter of light is less than the attraction of this matter for caloric.

Since we are thus naturally induced to consider light as a product or mixture of the producing matter of light and caloric, it will be necessary also to introduce this matter under a characteristic name into the nomenclature of natural elements. But the producing matter of light is not of itself luminous; it assumes this quality in the product of its mixture with caloric, and consequently it must be distinguished by the name of photogen from the Greek words $\varphi \omega \tau$ tos and $\gamma \varepsilon$ ivoual, which signify to produce light.

Light, and the matter that produces light, must also be as different from each other as cause and effect. The producing matter of light may be a component part of many objects in the world, and be distinguished by different qualities. It may also exist in the concrete form, mixed with other bodies; but it can never exist pure without mixture with other elements, because, as already observed, all elements in nature are in a continual state of mutual reaction, and exercise on each other an incessant power of attraction.

If the producing matter of light and caloric enter into mixture, the result is light; consequently caloric is that element which converts the producing nuatter of light into moveable or radiant light.

$$
\text { [To be continued.] }
$$

XXXVI. Fourteenth Communication from Dr. Thonnton relative to Pneumatic Medicine.

$$
\begin{aligned}
& \text { March 20, 1804. } \\
& \text { sir, }
\end{aligned}
$$

I SIR, cures long ago accomplished, which show also the permanency of the benefits received; and the present early case is, I think, a very striking example of the efficacy of the aërial remedy.

$$
\text { Case of Spasms. }
$$

Mrs. Gillespie, æt. 35, a married lady, for near a twelvemonth 